\title{
Characterization of variants of the gene encoding the p55 antigen in Pneumocystis from rats and mice
}

\begin{abstract}
Correspondence
Joseph A. Kovacs

jkovacs@nih.gov
\end{abstract}

Received 20 November 2002 Accepted 3 July 2003

\author{
Liang Ma,† Geetha Kutty, Qiuyao Jia† and Joseph A. Kovacs
}

Critical Care Medicine Department, Warren Grant Magnuson Clinical Center, National Institutes of Health, Bethesda, MD 20892, USA

\begin{abstract}
Variants of the $p 55$ gene in rat-derived Pneumocystis carinii have been identified and its counterpart in mouse-derived $P$. carinii f. sp. muris has been cloned. By PCR amplification of $P$. carinii genomic DNA, five variants were identified that differed from each other in size and sequence, primarily in the number and size of encoded amino acid repeats. For $P$. carinii f. sp. muris, a single PCR fragment (471 bp) was obtained, which contained an incomplete ORF encoding a 157 aa protein that was most similar to a p55 variant in $P$. carinii, with nucleotide and amino acid sequence identity of 79 and $68 \%$, respectively. Southern blot analysis revealed the presence of more than one copy of the p55 gene in both Pneumocystis species. Thus, like other Pneumocystis antigens, p55 exhibits polymorphism that could potentially benefit the organism in host interactions.
\end{abstract}

\section{INTRODUCTION}

Pneumocystis is an important opportunistic pathogen that causes severe pneumonia in patients with AIDS and other immunocompromising conditions. Two major groups of antigens have been identified in this organism by immunoblotting. One group, which is present as a broad band of 90$120 \mathrm{kDa}$, has been well-characterized as the major surface glycoprotein (MSG) in Pneumocystis organisms derived from rats, humans, mice, ferrets and rabbits (Graves et al., 1986; Walzer \& Linke, 1987; Gigliotti et al., 1988; Kovacs et al., 1989, 1993; Bauer et al., 1993; Kutty et al., 2001). The second group, which appears as a broad band of $45-55 \mathrm{kDa}$ in $P$. carinii and $35-45 \mathrm{kDa}$ in human-derived Pneumocystis jiroveci (Stringer et al., 2002), is less well-studied (Walzer \& Linke, 1987; Smulian et al., 1992, 1993, 2000). The gene that encodes a $45-55 \mathrm{kDa}$ protein of $P$. carinii, designated $\mathrm{p} 55$, has been cloned (Smulian et al., 1992, 1993). This gene is characterized by the presence of 10 repeats of a heptapeptide motif that is rich in glutamic acids near the C-terminus. Southern blot analysis has shown that this gene is present as a single copy. Unlike MSG, which resides on the outer surface of $P$. carinii, p55 is located within the cell wall (Broomall et al., 1998). Currently, the role of p55 in the biology and pathogenesis of Pneumocystis infection remains unclear. Theus et al. (1994) demonstrated a cell-mediated immune response to p55 in animals exposed previously to $P$. carinii. A

†Present address: Infectious Diseases Section, Department of Medicine, Louisiana State University Health Science Center, New Orleans, LA 70112, USA.

Abbreviation: MSG, major surface glycoprotein.

The GenBank/EMBL/DDBJ accession numbers for the sequences of Pneumocystis p55 variant genes are AF494448-AF494452. more recent study has shown that immunization with recombinant $P$. carinii p55 can afford partial protection against infection (Smulian et al., 2000).

Whilst screening a $P$. carinii cDNA library, we identified a DNA fragment that was highly homologous to the $P$. carinii p55 gene but lacked the heptapeptide repeats. We undertook to further characterize the $p 55$ gene in $P$. carinii and to clone the $p 55$ gene in mouse-derived $P$. carinii f. sp. muris.

\section{METHODS}

Pneumocystis organisms and DNA/RNA extraction. $P$. carinii organisms were isolated from the lungs of immunosuppressed rats, provided under contract by Indiana University (Indianapolis, IN, USA). P. carinii f. sp. muris organisms were isolated from the lungs of severe combined immune deficient (SCID) mice in our laboratory. Genomic DNA was extracted by treatment with proteinase K followed by phenol/ chloroform extraction, as described previously (Ma et al., 1999). Total RNA was extracted by using a RNAzol B Isolation kit (Tel-Test). Experimentation guidelines of the US Department of Health and Human Services and the NIH were followed in the conduct of this research.

PCR and DNA sequencing. Based on regions conserved between the previously reported $p 55$ sequence (Smulian et al., 1992, 1993) and a DNA fragment that we identified by sequencing randomly picked clones from a P. carinii cDNA library (Edman et al., 1989) (GenBank accession no. AF494450), we designed the primer pair PU947 and PD1637 (Table 1). PCR mixture $(50 \mu \mathrm{l})$ contained $100 \mathrm{ng}$ genomic DNA, $0 \cdot 5 \mu \mathrm{M}$ each primer, $0 \cdot 2 \mathrm{mM}$ dNTPs, $1 \times$ PCR buffer $(10 \mathrm{mM}$ Tris/HCl, $\mathrm{pH} 8 \cdot 3$; $50 \mathrm{mM} \mathrm{KCl} ; 2.5 \mathrm{mM} \mathrm{MgCl} 2$ ) and $2.5 \mathrm{U}$ AmpliTaq Gold DNA polymerase (PerkinElmer). Amplification was performed in a PTC-100 programmable thermal controller (MJ Research) with a touchdown cycling protocol as follows: $95^{\circ} \mathrm{C}$ for $8 \mathrm{~min}$, then 10 cycles of $1 \mathrm{~min}$ at $95^{\circ} \mathrm{C}, 2 \mathrm{~min}$ at $65^{\circ} \mathrm{C}$ (with a decrease by $1.5^{\circ} \mathrm{C}$ every cycle to reach $50{ }^{\circ} \mathrm{C}$ in the last cycle) and 2 min at $72{ }^{\circ} \mathrm{C}$, followed by 30 cycles of $1 \mathrm{~min}$ 
Table 1. Oligonucleotide primers and probes used in this study

\begin{tabular}{|c|c|c|}
\hline Oligonucleotide & Sequence $\left(5^{\prime} \rightarrow 3^{\prime}\right)$ & Description \\
\hline PU947 & GCAAAGACATTTTAGCAGAATCGTG & $\begin{array}{l}\text { Corresponding to positions } 280-304 \\
\text { of } p 55 \text { variant v3 (GenBank accession } \\
\text { no. AF494450) }\end{array}$ \\
\hline PD1637 & АCTCCTAATGTCATTCCTATAATTGCAC & $\begin{array}{l}\text { Complementary to positions } 769-796 \\
\text { of } p 55 \text { variant v } 3\end{array}$ \\
\hline$c p$ & GCAAAGACATTTTAGCAGAATCGTGTAAAAAAGTGCA & $\begin{array}{l}\text { Corresponding to positions } 280-316 \\
\text { of } p 55 \text { variant v } 3\end{array}$ \\
\hline$v 0 p$ & GATGAAAAGGAAAAGCCTACTGTAGAAGGGGGAGAA & $\begin{array}{l}\text { Corresponding to positions } 382-417 \\
\text { of } p 55 \text { (M77242) }\end{array}$ \\
\hline$c 1 r$ & TGCACTTTTTTACACGATTCTGCTAAAATGTCTTTGC & Complementary to $c p$ \\
\hline$v 01 r$ & TCAGGAGGAGGAGAAGGATGAGGACCAGGAAGACCTGCAC & $\begin{array}{l}\text { Complementary to positions } 14-62 \\
\text { of p } 55\end{array}$ \\
\hline$v 23 r$ & TCAGTAGGCCCTGGTTCTTCAGTAGGTGCTGGTTTTTCAGTAGTCGCTGGCTC & $\begin{array}{l}\text { Complementary to positions } 525-577 \\
\text { of } p 55 \text { variant v } 3\end{array}$ \\
\hline M39 & GAGAGCTGCTCAAAATTTAGTGATAGTTCTACCTTTACA & $\begin{array}{l}\text { Corresponding to } 14-52 \text { of } p 55 \\
\text { (AF494452) }\end{array}$ \\
\hline M472 & TCTACACGAACACCGTGACCTT & $\begin{array}{l}\text { Complementary to } 426-447 \text { of } p 55 \\
\text { (AF494452) }\end{array}$ \\
\hline
\end{tabular}

at $95^{\circ} \mathrm{C}, 2 \mathrm{~min}$ at $50^{\circ} \mathrm{C}$ and $2 \mathrm{~min}$ at $72{ }^{\circ} \mathrm{C}$. Each experiment included a negative control without template DNA. PCR products were sequenced either directly or after subcloning into vector pCR 2.1 as described previously (Ma et al., 1999). Sequence analysis was performed by using MacVector 7.0 software (Oxford Molecular). Nucleotide sequences obtained in this study are available from GenBank under accession numbers AF494448-AF494451 for P. carinii p55 variant genes and AF494452 for the P. carinii f. sp. muris p55 gene.
Southern blot analysis with P. carinii DNA. Based on the sequence alignment of the five $p 55$ gene variants in $P$. carinii (Fig. 1), we designed conserved and variant oligonucleotide probes, $c p$ and $v 0 p$ (Table 1). Probes were labelled with digoxigenin-dUTP by using the DIG Oligonucleotide Tailing kit (Boehringer Mannheim). Genomic DNA samples $(2.5 \mu \mathrm{g})$ were digested with SspI, AseI, XbaI or EcoRI. These enzymes recognize AT-rich sequences and have been found to cut Pneumocystis genomic DNA more frequently than other enzymes (Ma

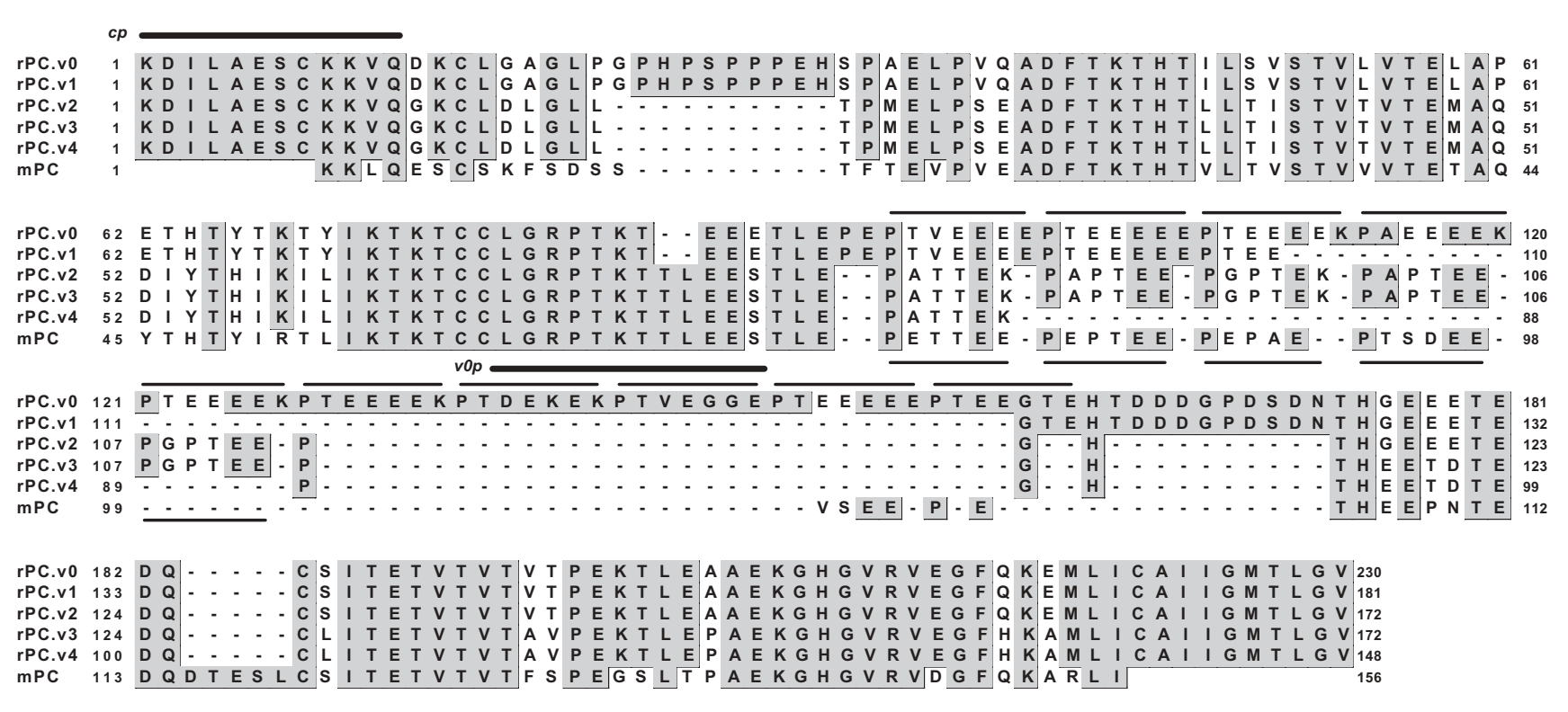

Fig. 1. Alignment of deduced amino acid sequences of p55 variants in P. carinii (rPC) and P. carinii f. sp. muris (mPC). Identical residues are shaded and boxed. The sequence of variant v0 is identical to that reported previously (Smulian et al., 1992). Lines above the sequences indicate heptapeptide repeats and lines below the sequences indicate hexapeptide repeats; the regions from which the sequences of probes $c p$ and $v 0 p$ were derived for use in Southern blotting are shown. GenBank accession numbers for the sequences of variants v1-v4 are AF494448-AF494451. 
et al., 1999; Kutty et al., 2001). No restriction sites for these enzymes were present in the sequences of probes used in this study. Digested DNA was separated by $1 \%$ agarose gel electrophoresis and transferred to a Nytran membrane (Schleicher \& Schuell). Blots were hybridized with probes overnight at $42^{\circ} \mathrm{C}$ by using DIG Easy Hyb hybridization solution (Boehringer Mannheim), washed twice in $2 \times$ SSC and $0 \cdot 1 \%$ SDS at room temperature for $5 \mathrm{~min}$ each, then twice in $1 \times$ SSC and $0 \cdot 1 \%$ SDS at $42{ }^{\circ} \mathrm{C}$ for 15 min each. Hybridization signal was detected by using a DIG Luminescent Detection kit (Boehringer Mannheim). Blots were stripped by incubating twice for $30 \mathrm{~min}$ each at $80{ }^{\circ} \mathrm{C}$ in stripping buffer that contained $50 \%$ deionized formamide, $5 \%$ SDS and $50 \mathrm{mM}$ Tris/ $\mathrm{HCl}(\mathrm{pH} \mathrm{7.5)}$ before rehybridizing with a different probe.

Southern blot analysis with $\boldsymbol{P}$. carinii f. sp. muris DNA. A DNA fragment was amplified from $P$. carinii $\mathrm{f}$. sp. muris genomic DNA by PCR with primers M39 and M472 (Table 1) and a PCR DIG Probe Synthesis kit (Boehringer Mannheim). Genomic DNA samples ( $9 \cdot 4 \mu \mathrm{g})$ were digested with EcoRV, HindIII, HpaI or XbaI. Subsequent procedures were done under the same conditions as described above, except that high-stringency washing was performed in $0 \cdot 16 \times$ SSC and $0 \cdot 1 \%$ SDS at $65^{\circ} \mathrm{C}$ for 15 min each.

Northern blot analysis with $\boldsymbol{P}$. carinii RNA. Total RNA was separated by $1.2 \%$ agarose gel electrophoresis in the presence of formaldehyde, transferred to a Nytran membrane (Schleicher \& Schuell) and hybridized at $42{ }^{\circ} \mathrm{C}$ overnight with probes $c 1 r, v 01 r$ or $v 23 r$, which were designed from conserved regions or specific variants. Washing and detection conditions were the same as for Southern blotting with $P$. carinii DNA.

\section{RESULTS AND DISCUSSION}

\section{p55 in P. carinii}

Whilst screening a $P$. carinii cDNA library, we identified a 906 bp fragment (GenBank accession no. AF494450), which contained a single incomplete ORF encoding a 269 aa protein that was homologous to the previously reported $P$. carinii p55 gene and protein (Smulian et al., 1992, 1993), with respectively 76 and $60 \%$ sequence identity in overlapping regions. Given that MSG and another $P$. carinii surface protein, PRT-1, are encoded by multi-copy gene families (Kovacs et al., 1993; Lugli et al., 1997; Russian et al., 1999), we wanted to determine whether p55-related proteins are encoded by multiple genes. We amplified $P$. carinii genomic DNA from a single rat isolate by PCR with primers (PU947 and PD1637; Table 1) that were based on regions conserved between these two sequences. PCR amplification resulted in two distinct bands. After subcloning of amplified products, we obtained 12 clones, which were subsequently sequenced. Alignment of these sequences identified closely related but unique $p 55$ variants, designated $\mathrm{v} 0-\mathrm{v} 4$, which consisted of five, one, one, three and two clones, respectively. Replicate clones of each variant were identical, except that two of the five clones of variant v0 contained a single nucleotide change at unique positions, which may be PCR artefacts. Fig. 1 shows an alignment of deduced amino acid sequences of the five variants. The sequence of variant $\mathrm{v} 0$ is identical to the published $p 55$ sequence (Smulian et al., 1992) and contains 10 repeats of a heptapeptide motif near the $\mathrm{C}$-terminus. Compared to v0, the other four variants $(\mathrm{v} 1-\mathrm{v} 4)$ differed primarily in the number and size of heptapeptide repeats, although sporadic single nucleotide polymorphisms were identified. Variant v1 differs from v0 by the presence of only two repeats of the same heptapeptide motif. Variants v2, v3 and v4 lack a 10 aa sequence near the $\mathrm{N}$-terminus compared to $\mathrm{v} 0$ and contain one or five repeats of a hexapeptide, rather than heptapeptide, motif. Variants v2 and v3 differ by nine amino acids in the C-terminus; $\mathrm{v} 3$ is identical to the sequence we identified initially. Variant $\mathrm{v} 4$ is the shortest sequence and contains only one hexapeptide motif. Additional clones were obtained by subcloning the PCR product from another rat isolate; they were found to correspond to the five variants, with no additional sequences being identified.

Southern blotting with $P$. carinii genomic DNA and a probe $(v 0 p)$ that was specific for variant $\mathrm{v} 0$ showed a single band with all four enzymes (Fig. 2), consistent with previous reports (Smulian et al., 1992). When the same blot was stripped and hybridized with a probe $(c p)$ that corresponded to a region conserved among all five $p 55$ variants, two bands (one of which corresponded to the single band in Fig. 2a) were seen for all enzymes except for EcoRI, which showed a single, high-molecular-mass band. These findings show that $P$. carinii has at least two copies of the $p 55$ gene and may have additional copies or allelic variants.

To determine whether the different variants were transcribed, Northern blotting was performed by using $P$. carinii total RNA (Fig. 3). Hybridization with a probe (c1r) from a region conserved among all five variants showed two bands of $\sim 1.5$ and $1.7 \mathrm{~kb}$ in size (Fig. 3 ). When the same blot was stripped and hybridized with a probe that corresponded to a region conserved between variants $\mathrm{v} 1$ and $\mathrm{v} 0$ (probe $v 01 r$ ) or between variants v2 and v3 (probe $v 23 r$ ), only one band was observed. Probe $v 01 r$ hybridized to the higher band and $v 23 r$ hybridized to the lower band. As only partial sequences were available for variants $\mathrm{v} 1-\mathrm{v} 4$, precise size of the corresponding mRNA could not be predicted. It is unclear whether individual bands present on the blot represent single variants. Given that available sequences for variants v2 and v3 are identical in size (487 bp) but differ in nucleotide sequence, the single band that hybridized to probe $v 23 r$ is probably a mixture of two transcripts of the same size. As the available DNA sequence of variant v1 is only 147 bp shorter than that of variant $\mathrm{v} 0$ in the overlapping region, they may not be separated well by the gel; thus, the single band detected with probe $v 01 r$ may also represent a mixture of two transcripts. However, the possibility that RNA expression levels differ among variants cannot be ruled out.

\section{p55 in P. carinii f. sp. muris}

PCR amplification of $P$. carinii $\mathrm{f}$. sp. muris genomic DNA with primers PU947 and PD1637 (Table 1) yielded a single band. Direct sequencing revealed a 471 bp fragment (GenBank accession no. AF494452) with an incomplete ORF encoding a 157 aa protein, which was most similar to variant v3 of p55 P. carinii (Fig. 1) with 79 and $68 \%$ identity in nucleotide and amino acid sequences, respectively. Southern 

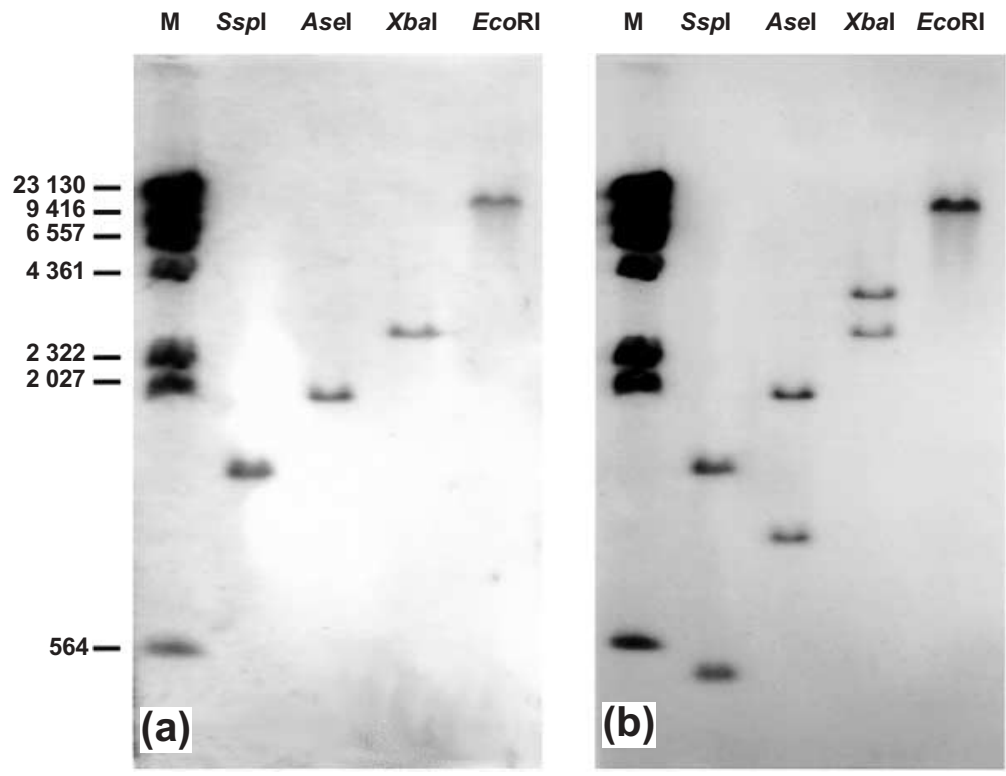

Fig. 2. Southern blot analysis of $P$. carinii genomic DNA digested with four restriction enzymes (indicated above each lane). (a) Hybridization with a probe $(v O p)$ that is specific for $p 55$ variant $\mathrm{vO}$; (b) the blot in (a) was stripped and hybridized with a probe $(c p)$ derived from a region conserved among five $p 55$ variants. Size markers are in lane M; DNA sizes (bp) are given on the left.

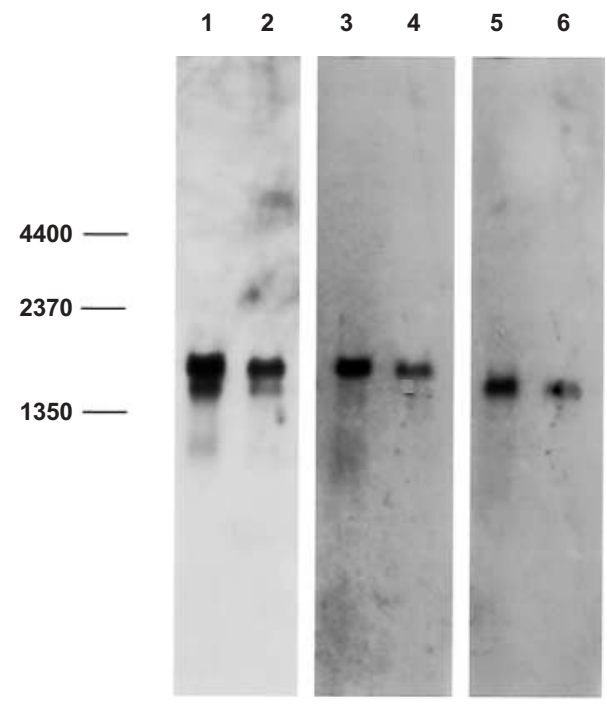

Fig. 3. Northern blot analysis of $P$. carinii RNA. Lanes 1 and 2 , hybridization with probe $c 1 r$, which is complementary to a region shared among all five p55 variants. Lanes 1 and 2 contained different amounts of $P$. carinii RNA, obtained from a single rat isolate. The blot was then stripped and hybridized with probe $v 01 r$ (lanes 3 and 4) or $v 23 r$ (lanes 5 and 6 ) derived from a region shared between variants $v 0$ and $v 1$ or between $v 2$ and $v 3$, respectively.

blotting with $P$. carinii f. sp. muris genomic DNA and a probe amplified by using primers M39 and M472 (Table 1) showed variable numbers of bands for four restriction enzymes (Fig. 4). Whilst we did not perform subcloning of the PCR product to obtain individual clones, variation of the number of bands in the Southern blot may reflect sequence variation or a complicated organization of multiple gene copies, which suggests that, like $P$. carinii, $P$. carinii f. sp. muris may have multiple copies or allelic variants of the $p 55$ gene.
These studies expand our understanding of the molecular organization of p55, which is one of the few antigens of Pneumocystis that has been characterized. Although the function of p55 is unknown, several studies have shown that p55 is capable of eliciting strong cellular and humoral immune responses in animals naturally infected with P. carinii (Smulian et al., 1992, 1993). Active immunization studies with recombinant p55 antigen have demonstrated partial protection against subsequent $P$. carinii infection in immunosuppressed rats (Smulian et al., 2000). Hence, p55 appears to play an important role in host-organism interactions. In the present study, we identified multiple variants of the $p 55$ gene, which are closely related but differ clearly. Whilst PCR or subcloning artefacts could have generated some of the variants that we have identified, identification of the same variants in organisms obtained from two separate animals strongly suggests that all variants are real. Whilst additional studies are needed to better characterize these variants, to try to identify additional variants and to localize the variants on chromosomes, it seems likely, based on variable sequence data as well as Southern and Northern blot studies, that p55 is encoded by multiple genes, similar to two other surface proteins, MSG and PRT-1 (Kovacs et al., 1993; Lugli et al., 1997; Russian et al., 1999). The presence of multiple $p 55$ genes supports a hypothesis that was derived from studies of MSG (Angus et al., 1996; Kovacs et al., 1993), i.e. that Pneumocystis has the potential for antigenic variability, which could play a role in immune evasion. Previous studies of rats exposed naturally to $P$. carinii have demonstrated that the repeat domain in the carboxyl portion of the p55 molecule is the target of both cellular and humoral immune responses, whereas the amino portion of this molecule is immunologically silent (Theus et al., 1994). In the current study, we found that p55 variants differed from each other primarily in the number and size of repeats, suggesting that Pneumocystis uses variation in the repeat region to evade host immune defences. 


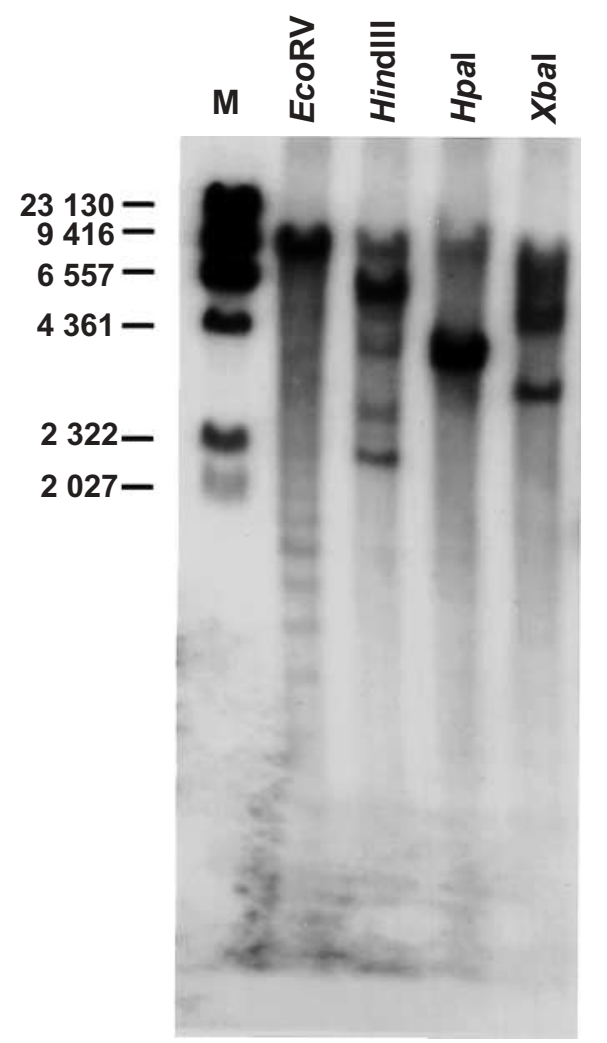

Fig. 4. Southern blot analysis of $P$. carinii f. sp. muris genomic DNA digested with four restriction enzymes (indicated above each lane). The probe was a DNA fragment amplified by PCR with primers M39 and M472. DNA sizes (bp) are depicted on the left.

In $P$. jiroveci, the antigen complex of $35-45 \mathrm{kDa}$ is the most common antigen found in lungs and bronchoalveolar fluid of patients with Pneumocystis pneumonia and is recognized strongly by serum antibodies of infected patients (Walzer \& Linke, 1987; Smulian et al., 1992, 1993). Thus, it would be of great interest to clone the $p 55$ counterpart in $P$. jiroveci. Previous studies have demonstrated that affinity-purified antibodies to the recombinant rat-derived $P$. carinii p55 antigen react with the $35-45 \mathrm{kDa}$ band of human-derived $P$. jiroveci, suggesting the presence of shared epitopes (Smulian et al., 1992). We attempted to amplify $P$. jiroveci genomic DNA by PCR with a number of different primer pairs that were designed from regions conserved among the six sequences shown in Fig. 1. However, no specific sequences were identified. In addition, no hybridization signal was observed in Southern blot analysis with $P$. jiroveci genomic DNA and a variety of probes (either oligonucleotides or PCR products), even under conditions of low stringency (data not shown). These results suggest that $P$. jiroveci does not have a homologue of p55 or that it has evolved substantially and does not have adequate homology to permit identification by these methods.

In conclusion, we have found five variants of the gene that encodes the p55 antigen in $P$. carinii. Our results suggest the presence of polymorphism in the $p 55$ gene and that at least two copies of this gene are present in the P. carinii genome. The $p 55$ gene in P. carinii f. sp. muris shows a high degree of homology to the $P$. carinii $p 55$ gene, but lacks the heptapeptide repeats. Novel approaches are needed to characterize the p55 gene counterpart in P. jiroveci.

\section{ACKNOWLEDGEMENTS}

We would like to thank Rene Costello and Howard Mostowski for their assistance. Part of this work was presented at the 7th International Workshops on Opportunistic Protists, Cincinnati, Ohio, 13-16 June 2001, abstract no. PO16.

\section{REFERENCES}

Angus, C. W., Tu, A., Vogel, P., Qin, M. \& Kovacs, J. A. (1996). Expression of variants of the major surface glycoprotein of Pneumocystis carinii. J Exp Med 183, 1229-1234.

Bauer, N. L., Paulsrud, J. R., Bartlett, M. S., Smith, J. W. \& Wilde, C. E., III (1993). Pneumocystis carinii organisms obtained from rats, ferrets, and mice are antigenically different. Infect Immun 61, 1315-1319.

Broomall, K. R., Morris, R. E., Walzer, P. D. \& Smulian, A. G. (1998). Zymolyase treatment exposes p55 antigen of Pneumocystis carinii. J Eukaryot Microbiol 45, 284-289.

Edman, J. C., Edman, U., Cao, M., Lundgren, B., Kovacs, J. A. \& Santi, D. V. (1989). Isolation and expression of the Pneumocystis carinii dihydrofolate reductase gene. Proc Natl Acad Sci U S A 86, 8625-8629.

Gigliotti, F., Ballou, L. R., Hughes, W. T. \& Mosley, B. D. (1988). Purification and initial characterization of a ferret Pneumocystis carinii surface antigen. J Infect Dis 158, 848-854.

Graves, D. C., McNabb, S. J., Worley, M. A., Downs, T. D. \& Ivey, M. H. (1986). Analyses of rat Pneumocystis carinii antigens recognized by human and rat antibodies by using western immunoblotting. Infect Immun 54, 96-103.

Kovacs, J. A., Halpern, J. L., Lundgren, B., Swan, J. C., Parrillo, J. E. \& Masur, H. (1989). Monoclonal antibodies to Pneumocystis carinii: identification of specific antigens and characterization of antigenic differences between rat and human isolates. J Infect Dis 159, 60-70.

Kovacs, J. A., Powell, F., Edman, J. C., Lundgren, B., Martinez, A., Drew, B. \& Angus, C. W. (1993). Multiple genes encode the major surface glycoprotein of Pneumocystis carinii. J Biol Chem 268, 6034-6040.

Kutty, G., Ma, L. \& Kovacs, J. A. (2001). Characterization of the expression site of the major surface glycoprotein of human-derived Pneumocystis carinii. Mol Microbiol 42, 183-193.

Lugli, E. B., Allen, A. G. \& Wakefield, A. E. (1997). A Pneumocystis carinii multi-gene family with homology to subtilisin-like serine proteases. Microbiology 143, 2223-2236.

Ma, L., Borio, L., Masur, H. \& Kovacs, J. A. (1999). Pneumocystis carinii dihydropteroate synthase but not dihydrofolate reductase gene mutations correlate with prior trimethoprim-sulfamethoxazole or dapsone use. J Infect Dis 180, 1969-1978.

Russian, D. A., Andrawis-Sorial, V., Goheen, M. P., Edman, J. C., Vogel, P., Turner, R. E., Klivington, D. L., Angus, C. W. \& Kovacs, J. A. (1999). Characterization of a multicopy family of genes encoding a surfaceexpressed serine endoprotease in rat Pneumocystis carinii. Proc Assoc Am Physicians 111, 347-356.

Smulian, A. G., Stringer, J. R., Linke, M. J. \& Walzer, P. D. (1992). Isolation and characterization of a recombinant antigen of Pneumocystis carinii. Infect Immun 60, 907-915. 
Smulian, A. G., Theus, S. A., Denko, N., Walzer, P. D. \& Stringer, J. R. (1993). A $55 \mathrm{kDa}$ antigen of Pneumocystis carinii: analysis of the cellular immune response and characterization of the gene. Mol Microbiol 7, $745-753$.

Smulian, A. G., Sullivan, D. W. \& Theus, S. A. (2000). Immunization with recombinant Pneumocystis carinii p55 antigen provides partial protection against infection: characterization of epitope recognition associated with immunization. Microbes Infect 2, 127-136.
Stringer, J. R., Beard, C. B., Miller, R. F. \& Wakefield, A. E. (2002). A new name (Pneumocystis jiroveci) for Pneumocystis from humans. Emerg Infect Dis 8, 891-896.

Theus, S. A., Sullivan, D. W., Walzer, P. D. \& Smulian, A. G. (1994). Cellular responses to a 55-kilodalton recombinant Pneumocystis carinii antigen. Infect Immun 62, 3479-3484.

Walzer, P. D. \& Linke, M. J. (1987). A comparison of the antigenic characteristics of rat and human Pneumocystis carinii by immunoblotting. J Immunol 138, 2257-2265. 